\title{
BENDING TEST OF ARTIFICIAL FEMURS WITH INTRAMEDULLARY NAIL
}

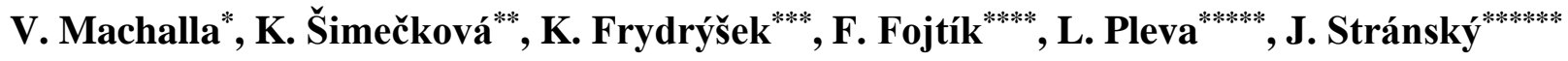

\begin{abstract}
This article represents a multidisciplinary approach of biomechanics (engineering + medicine) in the field of femoral nails made of austenitic stainless steel. The article deals with evaluation of the threepoint bend test of artificial bones with intramedullary femoral nails in accordance with ASTM F1264. Intramedullary nails are used in the femur to treat subtrochanteric fractures, femoral neck fractures or diaphysis fractures. The aim of this article is to evaluate and compare bending tests of two bones with implemented intramedullary nails for two types of case. The first case represents a healed bone fracture and the second case a bone with fracture.
\end{abstract}

Keywords: bending, femoral nail, biomechanics, bone fracture, artificial bone, measurement.

\section{Introduction}

Two artificial femurs (manufactured by SAWBONES) were subjected to the bending test, one was intact and the other two was cut twice in the subtrochanteric section, which simulated a subtrochantic line fracture (i.e. a three-fragment fracture of the proximal femur). An intramedullary reconstruction nail (manufactured by MEDIN a.s.) was implemented in both bones in cooperation with physicians of the Faculty Hospital Ostrava (Fig. 1).
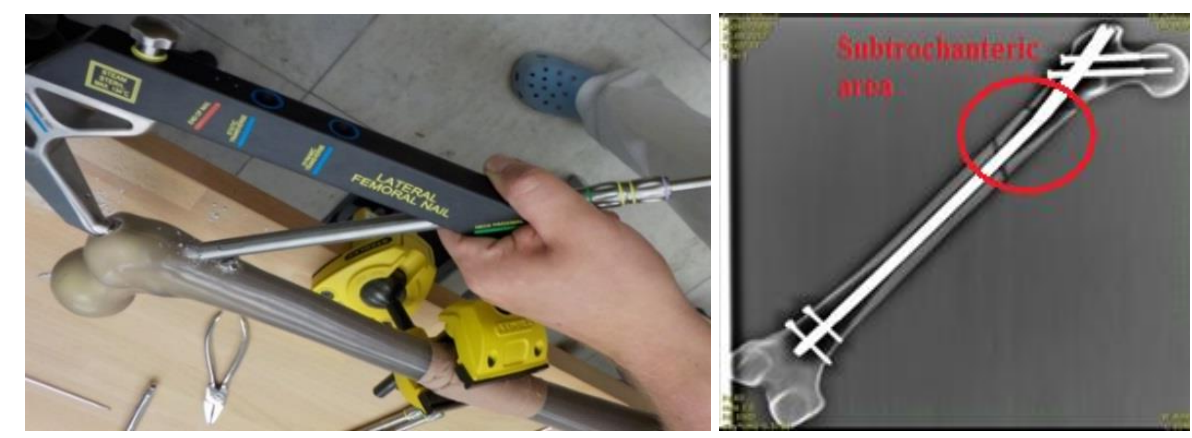

Fig. 1: (a) Application of femoral nail into artificial femur; (b) Rtg snapshot of artificial femoral bone with subtrochanteric fracture and femoral nail

MSc. Vojtěch Machalla, VSB - Technical University of Ostrava, Faculty of Mechanical Engineering, Department of Applied Mechanics, 17. listopadu 15/2172, 70800 Ostrava, CZ, vojtech.machalla@vsb.cz

** $\quad$ MSc. Kateřina Šimečková, VSB - Technical University of Ostrava, Faculty of Mechanical Engineering, Department of Applied Mechanics, 17. listopadu 15/2172, 70800 Ostrava, CZ, katerina.simeckova@ vsb.cz

*** Assoc. Prof. Karel Frydrýšek, PhD., ING-PAED IGIP, VSB - Technical University of Ostrava, Faculty of Mechanical Engineering, Department of Applied Mechanics, 17. listopadu 15/2172, 70800 Ostrava, CZ, karel.frydrysek@ vsb.czMSc.

**** MSc. František Fojtík, PhD., VSB - Technical University of Ostrava, Faculty of Mechanical Engineering, Department of Applied Mechanics, 17. listopadu 15/2172, 70800 Ostrava, CZ, frantisek.fojtik@ vsb.cz

****** Assoc. Prof. M.D. Leopold Pleva, Ph.D., Trauma Centre, University Hospital Ostrava, 17. listopadu 1790, 708 52, Ostrava, CZ \& Institute of Emergency Medicine, Faculty of Medicine, University of Ostrava, Syllabova 19, 70300 Ostrava, CZ, leopold.pleva@fno.cz

******* M.D. Jan Stránský., Trauma Centre, University Hospital Ostrava, 17. listopadu 1790/5, 708 52, Ostrava, jan.stransky@fno.cz 
Uninjured bone (healthy bone) was the bone after successful treatment. During the experiments, the progress of the loading force was recorded depending on bone deflection. All was to verify the reliability of osteosynthesis as a significant basis for clinical testing. Further experience (torsional tests of nails, femoral screws) are addressed in Frydrýšek et al 2018 and Frydrýšek II et al 2018.

\section{Examination by three-point bending of femur with a nail}

Femoral fixation (three-point bending test) is shown in Fig. 2. Measurement was carried out on the testometric M500-50CT device, which is owned by the Department of Applied Mechanics, Faculty of Mechanical Engineering, Technical University of Ostrava, Czech Republic.

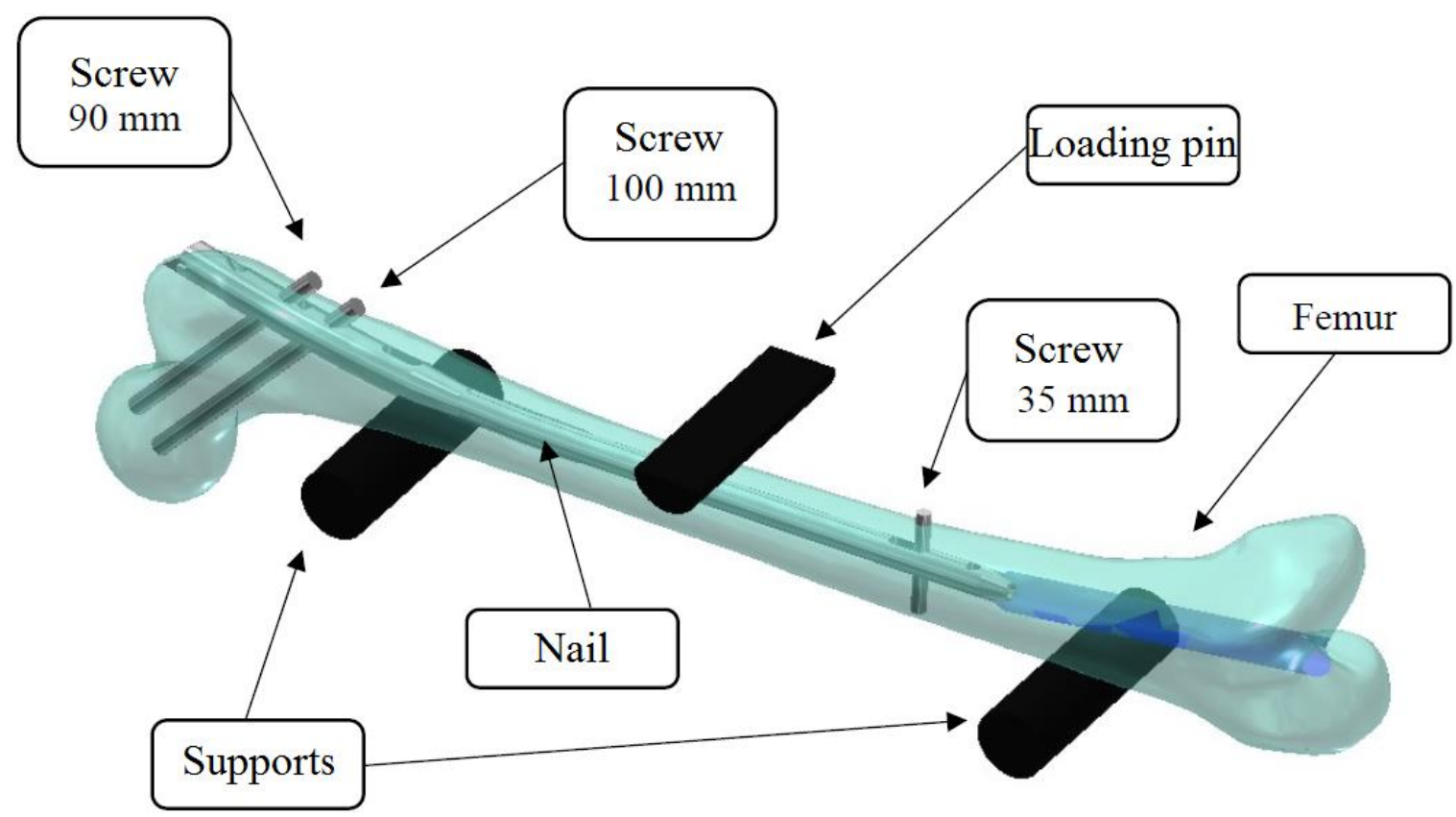

Fig. 2: Description of test, test specimen (femur with implanted intramedullary nail)

\section{Results}

\section{Femur No. 1 (healthy bone with nail).}

Dependence of the loading force on bone deflection with the intramedullary reconstruction nail is shown in Fig. 3. We tested artificial bone without fracture (healthy), which represented a healed bone.

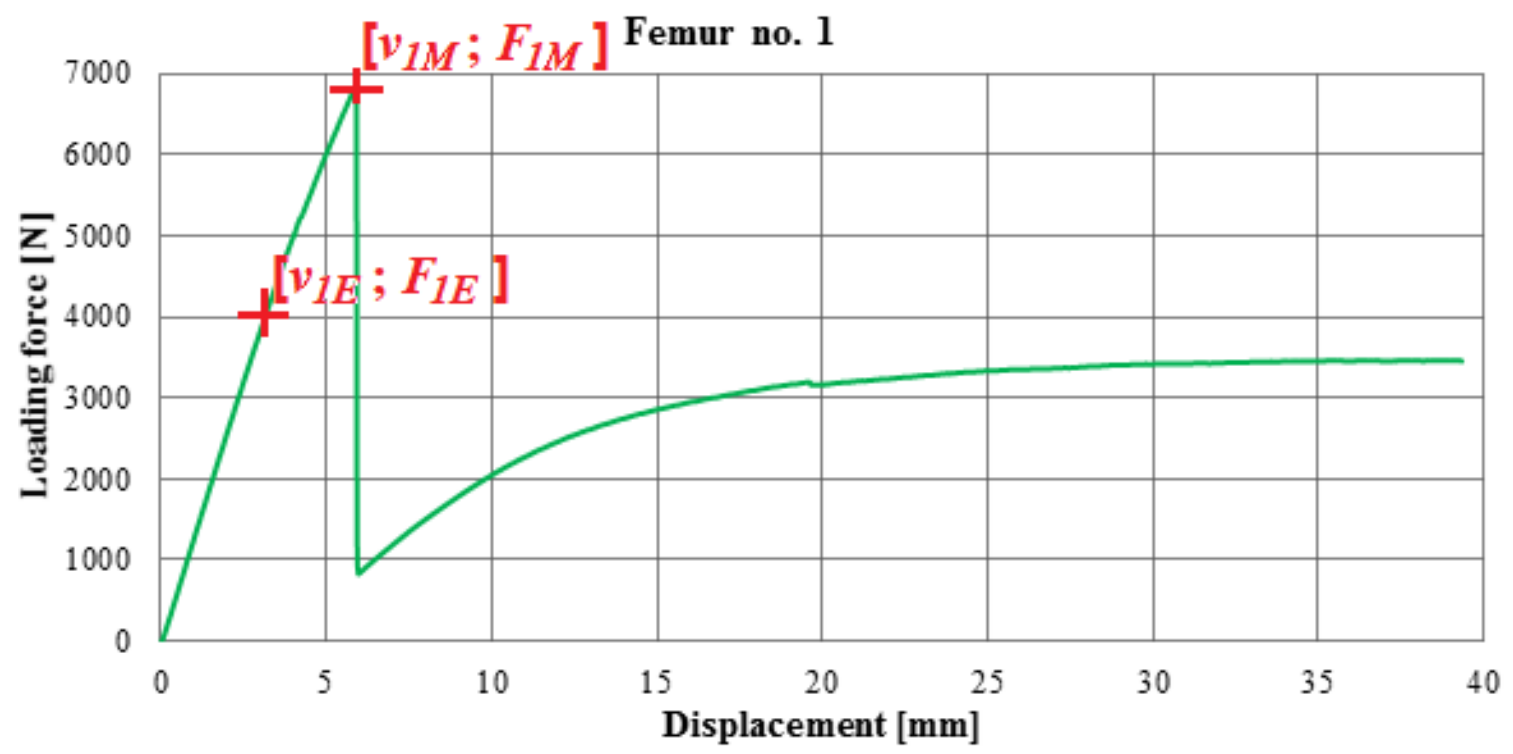

Fig. 3: Measurement - Dependence of loading force on displacement (femur no. 1) 
Bone fractured at the load force magnitude of $F_{1 M}=6885 \mathrm{~N}$ and deflection of $v_{1 M}=5.91 \mathrm{~mm}$ (Fig. 3, 4). There was a sharp drop in force to $844 \mathrm{~N}$, and then only the nail was bent. Limit of linear behavior has been established $\left[F_{1 E}=4003.5 \mathrm{~N} ; v_{1 E}=3.14 \mathrm{~mm}\right.$, see Fig. 3 . The bending stiffness in the linear region of healthy bone with the nail was calculated as

$$
k_{\text {bone } 1}=\frac{F_{1 E}}{v_{1 E}}=\frac{4003.5}{3.14}=1275 \frac{\mathrm{N}}{\mathrm{mm}} .
$$

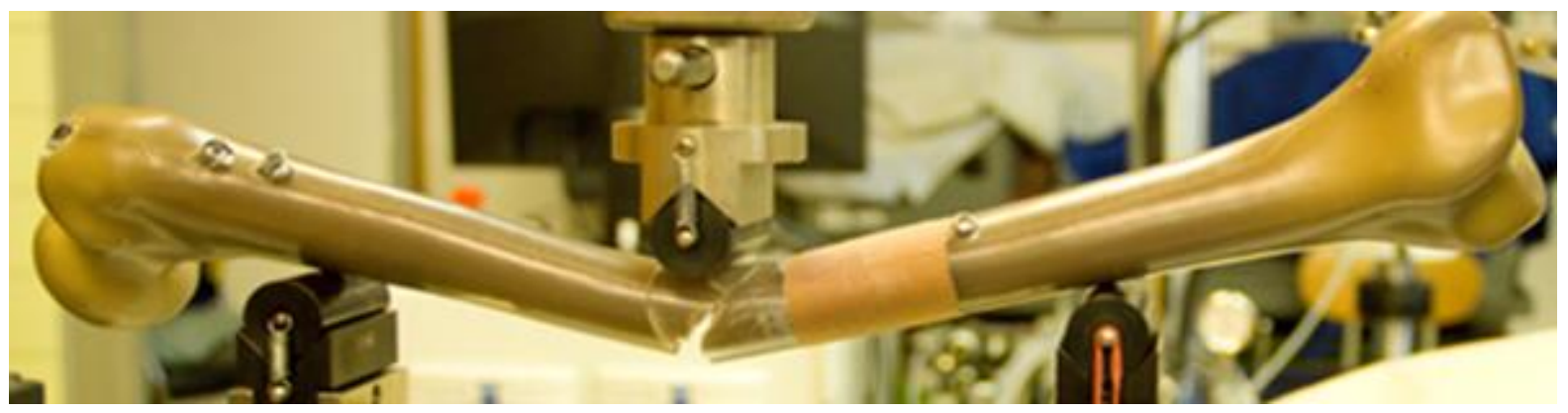

Fig. 4: Femoral fracture No. 1 induced by load (healthy bone with intramedullary nail)

Femur No. 2 (bone with fracture and nail).

Dependence of the loading force on bone deflection with the intramedullary reconstruction nail is shown in Fig. 5. We tested the artificial bone, which was cut twice in the subtrochanteric section, which was a subtrochanteric line fracture.

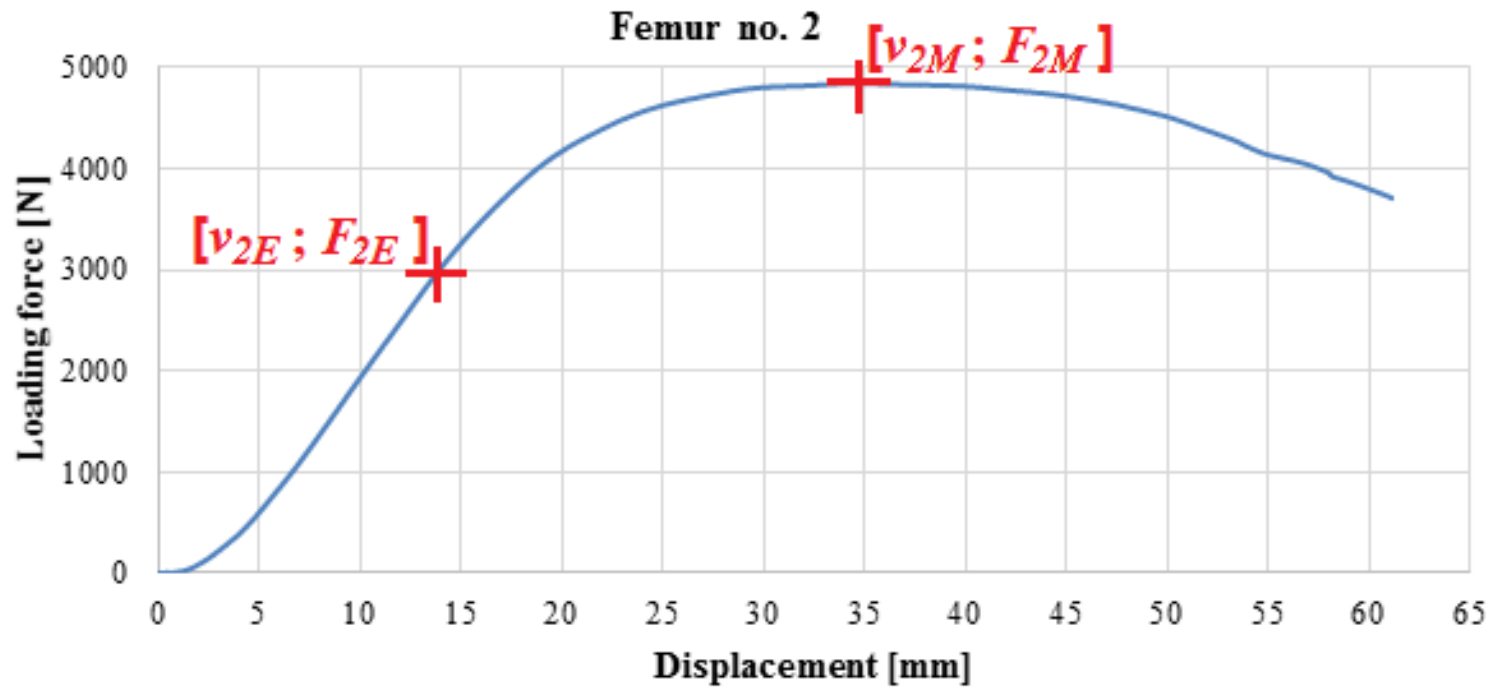

Fig. 5: Measurement - Dependence of loading force on displacement (femur No. 2)

In this case, the bone could not fracture because it was cut into 3 fragments at the beginning of the experiment. Only a free bone fragment was displaced, which got jammed in the rest of the bone and only the nail bent (Fig. 6). Maximum loading force assumed the value of of $F_{2 M}=4848.9 \mathrm{~N}$ at deflection of $v_{2 M}=34.51 \mathrm{~mm}$ (Fig. 5, 6). Limit of linear behavior has been established $\left[F_{2 E}=2999 \mathrm{~N}\right.$; $v_{2 E}=13.8 \mathrm{~mm}$, see Fig. 5. The bending stiffness in the linear region of fractured bone with intramedullary nail was calculated as

$$
k_{\text {bone } 2}=\frac{F_{2 E}}{v_{2 E}}=\frac{2999}{13.8}=217.3 \frac{\mathrm{N}}{\mathrm{mm}} .
$$




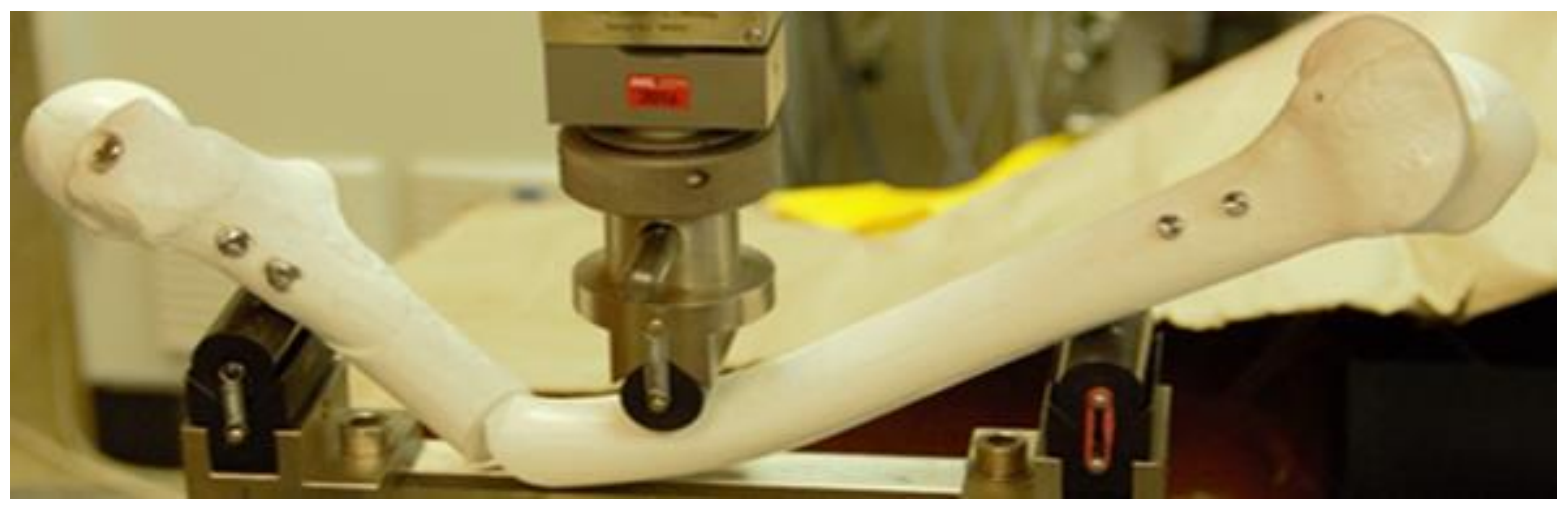

Fig. 6: Femoral fracture No. 2 induced by load (fractured bone with intramedullary nail)

\begin{tabular}{|c|c|c|c|c|c|c|c|c|c|}
\hline \multicolumn{5}{|c|}{ Linear area } & \multicolumn{4}{c|}{ Nonlinear area } \\
\hline \multicolumn{2}{|c|}{ Displacement } & \multicolumn{2}{|c|}{ Force } & \multicolumn{2}{c|}{ Bending stiffness } & \multicolumn{2}{c|}{ Displacement } & \multicolumn{2}{c|}{ Force } \\
\hline $\begin{array}{c}v_{1 E} \\
{[\mathrm{~mm}]}\end{array}$ & $\begin{array}{c}v_{2 E} \\
{[\mathrm{~mm}]}\end{array}$ & $F_{1 E}[\mathrm{~N}]$ & $F_{2 E}[\mathrm{~N}]$ & $k_{\text {bone } 1}\left[\frac{\mathrm{N}}{\mathrm{mm}}\right]$ & $k_{\text {bone } 2}\left[\frac{\mathrm{N}}{\mathrm{mm}}\right]$ & $\begin{array}{c}v_{1 M} \\
{[\mathrm{~mm}]}\end{array}$ & $\begin{array}{c}v_{2 M} \\
{[\mathrm{~mm}]}\end{array}$ & $F_{1 M}[\mathrm{~N}]$ & $F_{2 M}[\mathrm{~N}]$ \\
\hline 3.14 & 13.8 & 4003.5 & 2999 & 1275 & 217.3 & 5.91 & 34.51 & 6885 & 4848.9 \\
\hline
\end{tabular}

Tab. 1: Comparison of test results

Lower indices 1, 2 are related to the femur number (see also Fig. 3, 5).

\section{Conclusions}

Nowadays, complicated fractures of femur represent a serious and numerous problem in traumatology and orthopaedics, see also references by Hoza et al. (2018) and Frydrýšek (2017).

A bending test of two artificial bones was performed. The first bone was intact and an intramedullary nail was implemented in the same (represented a healed bone). The second bone was cut twice (representing line fractures in the subtrochanteric region) and a nail was implemented into it as well. The results of the bending test are shown in Tab. 1 and Fig. 3, 5 (maximum loading force in linear and nonlinear regions, bending rigidity, femoral deflection).

Performing these tests along with some other material tests can provide the basic information about material behavior suitable for producing femoral, intramedullary nails applied in traumatology/orthopaedics.

According to the results, the verifications of these intramedullary nails are enough sufficient. Therefore, these nails can be used for treatment of patients and will satisfy the ambitious demands of modern science. According to the rate $\frac{k_{\text {bone1 } 1}}{k_{\text {bone } 2}}=5.9$, the Femur no. 1 (i.e. healed bone with nail) is $5.9 \mathrm{x}$ stiffer than Femur no. 2 (i.e. bone with fracture and nail). This is good information for medicians and producers.

\section{Acknowledgement}

The authors gratefully acknowledge the funding from the Czech projects SP2019/100 and CZ.02.1.01/0.0/0.0/17_049/0008441.

\section{References}

Frydrýšek, K., Machalla, V., Fojtík, F., Pleva, L., (2018) Torsion test for femoral, humeral and tibial nails. Engineering mechanics 2018, 24, ISSN 1805-8256, pp 225-228.

Frydrýšek, K., Šír, M. and Pleva, L. (2018) Strength Analyses of Screws for Femoral Neck Fractures. Journal of Medical and Biological Engineering (2018), 38, pp 816-834.

Hoza, P., Hála, T., Pilný J. (2008) Fractures of Proximal Femur and their Solution, (Zlomeniny proximálního femuru a jejich řešení), Medicína pro praxi, 2008, 10 (5), ISSN 1214-8687, pp. 393-397

Frydrýšek, K. (2017) The Probabilistic Approach and its Practical Applications in Medical and Mechanical Engineering, in book RISK, RELIABILITY AND SAFETY: INNOVATING THEORY AND PRACTICE, edit. Walls, L., Revie, M., Bedford, T., Glasgow, SCOTLAND, CRC PRESS-TAYLOR \& FRANCIS GROUP, pp. 2453-2460, ISBN:978-1-315-37498-7. 